proceed to the technical colleges instead of, as at present, to the university. Nor is this view inconsistent with Sir Alexander Todd's suggestion that industry needs many more men with a good general science degree.

In this connexion, it is worth noting that Sir Eric Ashby has suggested that technology may hold the key to general culture. Unlike science, it involves an understanding of popular art and of commerce and psychology, something of morals and justice and some skill in the art of communication. It is the spirit of pursuit that matters, and we would be wise to explore such possibilities carefully. Further, there may be more substance in the criticism that the engineering research carried out at the universities is concerned with topics of little value to industry than the Committee on Scientific Manpower seems disposed to admit. All such matters are best discussed in the light of a review of the distribution of Great Britain's scientific effort, in terms not only of man-power but also of finance and materials, which should be a constant preoccupation of the Advisory Committee on Scientific Policy no less than of the Defence Research Policy Committee. The primary need is that these resources should be continually reviewed, not in relation to the efforts of other countries, but in relation to our own changing needs, in the broadest possible perspective. It is only in the light of such a factual survey that measures for the expansion of technical and university education or for any redistribution of effort and resources can be soundly planned.

\section{RECENT ADVANCES IN NUCLEAR SCIENCE}

Progress in Nuclear Physics

Edited by Prof. O. R. Frisch. Vol. 4. Pp. vii +379. (London and New York: Pergamon Press, Ltd., 1955.) 70s. net.

VOL. 4 of this series, offering a survey of various fields in nuclear physics, seems the most readable one of those published up to now. All the articles are of interest, the problems properly formulated and the English of great clarity, due no doubt to the pains taken by the editor. The topies dealt with are : photodisintegration experiments with nuclear emulsions (E. W. Titterton); scintillation spectrometer statistics (Ernst Breitenberger); meson phenomens and the meson theory (R. H. Dalitz); focusing in high-energy accelerators (T. G. Pickavance); isotopic spin and nuclear reactions (W. E. Burcham); heavy ions of high energy (D. Walker); nuclear properties of the very heavy elementis (J. O. Newton); the preparation and chemistry of the transuranium elements (H. A. C. McKay and J. Milsted); and rieutron spectroscopy (D. J. Hughes).

To pick out one or the other article for comment seems unfair, but one has one's preferences. The summary on photographic plate studies of the nuclear photo-effect (E. W. Titterton) is excellent, as it does not go too much into technical details but shows up the power of the photographic-plate method, discusses the main results and very thoroughly the theoretical implications. A particularly useful contribution deals with the statistics of the scintillation counter (E. Breitenberger). Those very versatile tools, the 'generating functions', are developed to the point where a physicist can use them, and the author has followed, with their help, the many statistical effects which influence the width of a spectral line caused originally by a monochromatio quantum radiation. It is to be hoped that this article, which seems more like a piece of research, will encourage physicists to treat their fluctuation problems with the help of generating functions. Another impressive piece of reporting comes from the pen of Prof. Burcham on the use of isotopic spin. The crystal-clear and didactically outstanding introduction to the, at first, abstract notion of isotopic spin is very valuable, since the concept is so very useful in low- and high-energy nuclear and meson-physics. I would appeal to the theoretical physicists to study it closely and find out how not to create a potential mountain for the experimentalist when explaining theoretical concepts.

The two companion articles on the physics and the chemistry of the very heavy elements are very timely ; but it is a pity that they were written just before a large mass of information was being declassified for the Geneva Conference. For a physicist it is fascinating to watch the chemist separate in cation-exchange columns such tough problems as mixtures of the rare earths or the actinide series (see p. 321). This section is of considerable interest to the chemist and the physicist. The printing and reproduction are excellent.

E. Bretscher

\section{SEXUAL MORALITY}

Sex and Morality

By Prof. Abram Kardiner. Pp. 274. (London : Routledge and Kegan Paul, Ltd., 1955.) 18s. net. Homosexuality

By Dr. D. J. West. Pp. xiii +145 . (London : Gerald Duckworth and Co., Ltd., 1955.) 15s, net.

$T^{T}$ is a surprising thing that we do not know for certain what is the normal psychosexual development of a human being, or even an animal in the wild. We know, of course, through Freud's patient researches, how human beings develop in our culture and, through anthropological investigations, we have some idea how they develop psychosexually in other cultures; but it is impossible to isolate man from his environment and discover how he would grow up uninfluenced by custom.

Prof. A. Kardiner, in his interesting book "Sex and Morality", points out various developments such as liberalism which made women feel they should be freer, the romantic movement which stressed equality, and finally feminism which urged that women should have careers the same as men. These were protests against previous oppression, but produced profound effects on morality. The invention of successful contraceptive devices and medical advances against venereal diseases freed women from moral impediments and tended to break down custom still further.

Women's attempt to escape from the kitchen and the home and to substitute a career for family life led to compromise and often failure. When there were children there was inevitably some rejection of them, and such rejection has a profound effect on development. It can lead to aggression, which may appear later so that the child becomes a juvenile 